\title{
Does one shoe fit all? Time to Consider Body-Weight Wise Regimens to Treat TB Patients under DOTS - A Study from South India
}

\author{
Article by Prashant Bhat \\ Department of Health \& Family Welfare, Government of Karnataka, India \\ E-mail: bhatp74@gmail.com
}

\begin{abstract}
Background: India accounts to one fifth of the global TB burden. It is implementing all the components of WHO STOP TB strategy for TB control through the Revised National TB Control program (RNTCP) since 1997. However, RNTCP neither has a policy to monitor TB treatment based on body weight of the patients nor provisions for nutritional support to TB patients with low body weight. Recent evidences also show that relapse and MDR rates are high in India compared to other High TB Burden Countries (HBCS). Karnataka (population 63 million) is a southern State in India implementing RNTCP with overall annual TB case notification of $\sim 103$ per 100,000 population and success rate of $\sim 83 \%$ for new smear positive (NSP) cases below the global benchmark of $>85 \%$. Our hypothesis is that unfavorable treatment outcomes were more common among patients with lower body weight at initiation of treatment. We studied the relapse and MDR rates in India in 2011 from the published data, in comparison to other HBCs and the outcomes of TB patients treated under RNTCP in 2012, in two districts of Karnataka with the specific objective to examine the effect of initial body weight on treatment outcomes.

Methodology: In this record based cohort study, we reviewed two separate data set. In first, we examined the published data on all TB patients treated nationally (covering 1.25 billion population) in 2011 for published relapse and MDR rates. In second, we examined treatment cards of all adult TB patients weighing more than $30 \mathrm{kgs}$, registered for treatment in the year 2012 from two districts (Gadag and Uttara Kannada) of Karnataka covering 2.6 million populations.

Results: Part 1: National level: Of the total 754,829 incident TB cases (NSP plus Reinfection/Reactivation) treated in India, 112,508 (15\%) had relapse. MDR TB among retreatment cases was $15 \%$.

Part 2: Study districts: Of the 2147 adult patients (with initial body weight more than 30 $\mathrm{kgs}$ ) enrolled for treatment, the mean body weight was $43 \mathrm{kgs}$ (IQR 38-48 kgs), with p5 at 32 kgs and p95 at $58 \mathrm{kgs}$. Outcome "died" was highest among patients weighing between 30$39.9 \mathrm{kgs}$ across all the types of TB (Chi square=13.82, $d f=2, P<0.001)$; failure was also highest in this weight band among retreatment cases (Chi square $=6.72 d f=2, P<0.05$ ).

Conclusion: Standardized treatment regimen in India had high relapse and MDR rates. Lower body weight at initiation of treatment is associated with higher risk of death across all types of TB and with failure among retreatment cases. While further study is indicated to explore the reasons for these findings, clearly, National TB Programs should have strategies to monitor treatment based on initial body weight and consider nutritional support to TB patients with low body weight at diagnosis to improve survival.
\end{abstract}

Keywords: Tuberculosis, Body-weight, TB-Treatment, Nutrition, RNTCP.

\section{Introduction}

India is second most populous developing country in the world with 1.25 billion populations. ${ }^{1}$ India, as any other developing countries, has high rates of communicable diseases. ${ }^{2}$ It also represents a quarter of all global TB burden. ${ }^{3}$ Overall, India contributes 1.9 million projected new TB cases, of which about $85 \%$ are projected to be adults ( $>15$ years). ${ }^{4}$ 
Revised National TB Control Program (RNTCP) has been started in India since 1997 with the prime objective to control TB to an extent that it will be no more a public health problem. While RNTCP treats about a million TB cases every year, another million cases go unnotified. ${ }^{5,6,7}$ There are published literatures stating that these cases are treated outside the Government sponsored TB control program. ${ }^{8}$ RNTCP advocates DOTS endorsed by WHO, using standardized treatment regimen. The Standardized treatment regimen in India uses only single weight band for adult patients above 30 kilograms. The program caters the pediatric TB patients as well under its ambit, but has six weight bands to cover between 6-30 kilograms. Outside RNTCP, patients are being treated with Fixed Drug Combinations (FDCs) based on body weight both for pediatric and adult regimen, though it's standards are being questioned. . $^{910,11}$

In the recent years, TB control is becoming much more complex with the emerging comorbidities like HIV, DM and other related disease modulating conditions. The success rate in RNTCP has remained at $86-87 \%$ for the last 5-6 years and is not increasing. There are growing concerns about the stagnant success rate. Also, there are evidences to show that the primary drug resistant TB cases are increasing in recent years. WHO's STOP TB envisages to end TB by 2035, with the target to reduce TB related death by $95 \%$ compared to 2015 level. ${ }^{12}$ this target appears difficult to achieve if the same state of affairs continue. There is an acute need to find out reasons for the adverse outcomes and find solutions for the same.

We had a field observation that the TB patients with low body weight had adverse treatment outcomes, although the same was never systematically analyzed. There was growing concern in the field workers that one regimen for all the patients weighing more than $30 \mathrm{kgs}$ is not suitable. The hypotheses were that the regimen is formulated and suitable for patients weighing between 40-50 kgs and the adverse treatment outcome in low body weight is directly associated with the inappropriate dosage of the regimen for this weight.

This leaves hypotheses as to whether the program should rethink on optimizing drug dosage for adult TB patients using standardized weight-band-wise treatment regimens (or individualized regimen). There has been published literature which showed high association of Body Mass Index with TB mortality. ${ }^{13}$ However, there have been no efforts in India to systematically look in to the outcomes of treatment in different weight bands to say all adults with different body weights fit in to same dosage. Further, there has been no systematic analysis of weight band wise outcome of TB patients treated with standardized DOTS in India.

\section{Aims and objectives}

We sought to evaluate the outcome of these TB patients who were treated with standardized DOTS regimen, with the specific objectives to assess, a) overall relapse rate among patients treated with DOTS in India in 2011 in comparison with rest of the countries, b) the treatment outcomes among adult patients treated with DOTS in Gadag and Uttara Kannada districts in 2012, and c) to compare the treatment outcomes among weight band wise adult TB patients (>30 kgs, >15 years) treated with DOTS in Gadag and Uttara Kannada districts in 2012.

\section{Methods}

\section{Study design}

It was a cross sectional cohort analysis using program secondary data.

Means of collection of information: - Part 1 of the study used the published data derived from Global TB Report 2012 and TB India 2011. Part 2 of the study used the data collected from the Treatment cards of TB Patients treated in Gadag and Uttara Kannada districts of Karnataka, India.

\section{Study settings}


The study has two parts. First part involves published program data in Global TB Report 2012, where the data from different countries are tabulated systematically and compared for analysis of relapse and MDR rates for different countries. The second part includes the program data collected in two districts of Karanataka, Gadag and Uttara Kannada, to evaluate systematically the treatment outcomes in general and weight band wise outcomes in perticularly.

\section{General setting}

India is one of the South East Asian countries situated surrounded by China and Nepal in its north east, Pakisthan in its North West, Bangladesh and Mayanmar in its east, and Arabian Sea in its south, west and eastern borders. It is second most populous country, next to China with 1.25 billion population. With 29 states and seven Union Terrories, India stands seventh large nation land-wise. India contributes to one fourth of Global TB burden with 1.9 million TB cases emerging every year. ${ }^{3}$

Gadag is a small district in north part of Karnataka (a south Indian state) with close to one million population. The district borders Bagalkot on the north, Koppal on the east, Bellary on southeast, Haveri on southwest, Dharwad on west and Belgaum on northwest. The district has two sub district TB program management units (Tuberculosis Units - TUs) and 28 peripheral health units to manage TB cases under RNTCP (Figure 1).

Uttara Kannada is a costal district in northwest part of Karnataka, with 1.5 million population, 11 sub-district revenue blocks approximately 4,000 sqm area, most of which are densely covered by forest. It borders Goa and Belgaum on the north, Darwad and Haweri on the east, Shivmogga and Udupi on the south and Arabian Sea on the west. The district has four sub-district TB program management units (TUs) and 73 peripheral health institutes to cater for TB patients under the program (Figure 1).

\section{Revised national tuberculosis control program}

RNTCP was started in India in 1997 scaled up to cover the whole country by $2004 .{ }^{14}$ Major Goal of the program was to curtail TB to an extent that it is no more a public health problem in India. Recently a TB free India with zero deaths, disease and poverty due to Tuberculosis has been envisaged in RNTCP with a shift of Goals to achieve a rapid decline in burden of TB, morbidity and mortality while working towards elimination of TB in India by $2025 .{ }^{15}$ India's RNTCP treats close to one million TB cases, far more than any health programs in the world. ${ }^{4}$ RNTCP adopts WHO recognized standardized DOTS regimen for treating TB patients. While the regimen for pediatric treatment has six weight bands, there is only one weight band for the adults weighing above $30 \mathrm{kgs} .{ }^{16,17}$

Under RNTCP, all the TB patients who are diagnosed and put on treatment are allotted a treatment card and registered by a designated TB supervisor (Senior TB supervisor - STS) in the TB register. While the TB register captures only vital events of each patient, the treatment card would capture all the events of the individual TB patients, including their weight at various stage of treatment course. Treatment card thus forms the base document for individual patients. The treatment cards are kept at the institute where $s /$ he is being treated till outcome. Once outcome is given, the card is taken by the STS to archive at TU. These patients are followed up on a quarterly cohort basis for their treatment, follow up investigations and treatment outcomes, and reported to the state and the central level data repository on a quarterly basis.

\section{Study population}

For first objective all adult ( $\geq 15$ years) TB patients registered for treatment under RNTCP nationwide in 2011. For second and third objective, all adult TB patients registered under DOTS between January - December 2012 in Gadag and Uttara Kannada districts, Karnataka.

\section{Source of data collection}

1. For objective one, the source is Global TB Report 2012 and TB India 2011. 
2. For second and third objectives, TB treatment cards of individual patients with the Senor TB Treatment Supervisors (STS) of these districts

\section{Data variables, data collection and data quality}

For first objective, published consolidated data were abstracted from Global TB Report 2012 and TB India 2011. For second and third objectives, District name, TU Name, TB number, Weight, Type of TB, Regimen, TB Outcome, HIV status were collected from individual treatment cards at two study districts. Data thus collected were double entered in EpiData software (Version 3.1, EpiData association, Denmark) and validated. Any discrepancy was corrected with reference to primary data.

\section{Data analysis}

Validated data were analyzed using EpiData software (Version 2.2.2.183, EpiData Association, Denmark). Outcomes like cure rates, success rates, failure rates, with reference to weight bands as recommended by WHO were analyzed. Differences in outcomes in different weight bands (lower and higher weight bands) were assessed. Odds ratio was calculated with 95\% Confidence Interval for comparing the relapse rates of various nations. Chi-square test were calculated and level of significance was kept at $5 \%$.

\section{Ethical issues}

Departmental approval obtained from the State TB Cell, Karnataka. As the study involves routinely collected program data reviewing the records and reports available with the program, without personal identifiers and intervention, written consent from the study participants were not deemed necessary.

\section{Results}

\section{Relapse and MDR at the National Level:}

The proportions of relapse cases in high TB burden countries (HBCs) are summarized in Table 1. While the absolute number of relapse cases in India is equal to the number in all other HBCs together, the proportion is more than double that of rest HBCs combined. Odds ratio of relapse in India compared to other HBCs combined is 2.32 (95\% CI 2.30-2.34) which is statistically significant. India's contribution for notification of new smear positive TB cases is $30 \%$, whereas that of relapse is $50 \%$ (data not tabulated). The rate of relapse has further amplified in some states where it is up to the tune of $20 \%$ (data not tabulated). Internationally accepted relapse rate is $<5 \%$.

The proportions of MDR TB cases among the retreatment cases in HBCs are summarized in Table 2. This proportion is 15\% in India. Although rates of MDR are high among TB cases who failed first regimen, absolute number of MDR cases are high among relapse cases accounting to $>40 \%$ of all MDR cases (data not tabulated).

TB Treatment outcomes at Gadag and Uttara Kannada, Karnataka:

The demographic and clinical profile of TB patients selected for the study from Gadag and Uttara Kannada districts of Karnataka is summarized in Table 3. Of the 2147 adult patients (with initial body weight more than $30 \mathrm{kgs}$ ) enrolled for treatment, the mean body weight was $43 \mathrm{kgs}$ (IQR 38-48 kgs), with p5 at $32 \mathrm{kgs}$ and p95 at $58 \mathrm{kgs}$. While two thirds $(1456,66 \%)$ were males, almost half were in reproductive age-group (25-45 years) $(499,40 \%)$. Of the six TUs included, Gadag and Ron (Both Gadag District) had over half of all the cases. Majority were new cases $(1769,80 \%)$ and HIV positivity rate was $12 \%$ (274).

Treatment outcome in study districts:

The initial body weight and treatment outcomes of TB patients included in two study districts are summarized in Table 4. About one third of the TB patients treated had initial weight less than $40 \mathrm{kgs}$ in both the districts (Gadag: 39\% and Uttara Kannada 32\%). While Gadag reported 10\% (108) deaths and 9\% (106) defaults among treatment outcomes, Uttara 
Kannada reported 5\% (58) deaths and 6\% (69) defaults. The treatment failure reported in Gadag and Uttara Kannada were $2 \%$ and $4 \%$ respectively.

Weight-band wise treatment outcomes in study districts:

The initial body weight wise treatment outcomes of TB patients treated in 2011 in two study districts are summarized in Table 5. Overall, the death rate among new TB patients with initial body weight less than $40 \mathrm{kgs}$ was $8.8 \%$, which was significantly high when compared to the reference body weight of $40-50 \mathrm{kgs}$ (Chi square $=7.17, \mathrm{df}=2, p<0.05$ ). Similarly, death rate among retreatment TB cases with initial body weight less than $40 \mathrm{kgs}$ was $14.1 \%$, which was significantly high when compared with patients weighing 40-50 kgs (chi square $=8.95, \mathrm{df}=2, p<0.05$ ). TB patients initially weighing less than $40 \mathrm{kgs}$ had significantly higher chance of failing the treatment among re-treatment TB cases (Chi square $6.72, \mathrm{df}=2, p<0.05$, Reference: $40-50 \mathrm{kgs}$ ). Body weight had deteriorated in most of these retreatment cases during the treatment $(77,55 \%$, data not tabulated). Overall there was higher proportion of defaults among new TB cases weighing below $40 \mathrm{kgs}(7.1 \%)$ when compared with rest weight bands, though it was not statistically significant.

\section{Discussion}

To our knowledge, this is the first paper to be written to describe the un-favorable outcomes of TB treatment in patients with low initial body weight from India (As confirmed by PubMed search on $17^{\text {th }}$ May 2017). There were some important findings. First, the very fact that the relapse rate is high in India compared to rest of the high TB burden countries combined is a considerable evidence showing something wrong in the TB treatment strategy. Second, there exist very high rate of MDR TB among re-treatment TB cases in India. Third, un-favorable outcomes like death; default and failure were significantly high in patients with low initial body weight, which is more pronounced in re-treatment cases.

High rates of relapse in TB patients treated under RNTCP suggest that there is something wrong in the treatment regimen used. India use WHO endorsed standardized DOTS regimen for treating tuberculosis under its RNTCP. ${ }^{17}$ While these standardized dosage is fixed based on average body weight of $50 \mathrm{kgs}$, there is no evidence so far, whether this dosage is sufficient to treat a patient who is weighing more than $50 \mathrm{kgs}$ at the time of start of treatment. Under RNTCP, there is provision to add Rifampicin if the body weight is over $60 \mathrm{kgs} .{ }^{17}$ But it is logical to think that, just adjusting one drug for optimum dosage without any adjustment for other drugs may have sub-lethal effect over the persisters, which flare up once the treatment is over, leading to relapse. This relapse rate in India is highly alarming with reference to the internationally accepted relapse rate $(<5 \%)$, i.e., over three times the accepted limit. ${ }^{18}$

In India, MDR cases among retreatment cases are also very high at $15 \%$. The high rate of MDR can also be explained along the similar line. Body weight among other factors plays a major role in bioavailability of drugs. ${ }^{19}$ Lower bioavailability of drugs tends to result in failure of the regimen. ${ }^{20}$ Dose adjustment of only Rifampicin may result in mono-therapy in TB patients with higher initial body weight leading to amplification of resistance to Rifampicin. In presence of extensive INH resistance up to the tune of $40 \%$ in India ${ }^{21,22}$ Rifampicin resistance tends to enhance MDR rate, which is quite detrimental to the RNTCP.

The existence of significant adverse outcomes in TB patients with low initial body weight treated under the program shows that the standardized regimen with same dose for all weight above $30 \mathrm{kgs}$ has some problem. It might be either due to adverse drug reaction or due to drug intolerance. A recent study by Jindani A et.al., showed that the dosage of Rifampicin when increased from 10 to $15 \mathrm{mg} / \mathrm{kg}$ has increased significant side effect. ${ }^{23}$ Verbal autopsy in few death cases in this category suggests that, higher doses of anti-TB drugs further reduce appetite, thus fueling malnutrition, leading eventually to death. The standardized treatment under RNTCP has seven pills per dose during initial phase of intensive treatment, which extends to two to four months and two to three pills per dose during the later phase of continuation which, extends to at least four to five months. Many patients and private health care providers during our field visits complain that this high pill burden itself leads to reduced 
appetite fueling already deteriorated body weight due to the disease. Most of the low body weight patients also had added co-morbidities, thus adding additional drugs for the treatment of co-morbidities, increasing the pill count further. This might be one of the reasons for high lost to follow up during the treatment.

High failure rate among low body weight re-treatment cases might be due to severe malnutrition fuelled during first regimen. Most of these re-treatment cases face further deterioration in body weight during the second regimen treatment. This accentuated weight loss may be either due to anorexia secondary to long time treatment during first regimen, advancement in disease itself or due to malnutrition induced mal-absorption. Severe malnutrition would have associated mal-absorption of the food as well as drugs. This forms a triage of vicious circle, mal-absorption induced reduction in weight, low bioavailability leading to disease progression, malnutrition due to mal-absorption with advancement in disease. Severe malnutrition would also result in reduced immunity, thus leading to comorbidities. ${ }^{24}$ Many also die due to severe malnutrition and or co-morbidities.

All the TB patients treated under the RNTCP ambit in the study population (National level for Part 1 and two study districts for Part 2) are included under the study without giving room for any sampling error. The study adhered to STROBE (STrengtheing Reporting of OBservational studies in Epidemiology) Guidelines and sound Ethical considerations. ${ }^{25,26}$ The study used a powerful data collection instrument structured through EpiData entry software with several checks for collecting efficient and quality assured data to minimize data entry errors. ${ }^{27}$ Nevertheless the study had few limitations. We used secondary data available in the Public Health Program and hence the inherent errors as with any other secondary data cannot be ruled out. The socio-economic parameters were not available in the data and hence could not be included.

The study has three clear policy implications. First, the Government must consider redesigning treatment regimens with weight band wise Fixed Drug Combinations (FDCs) to reduce pill counts and optimize dosages along all weight bands. FDCs also facilitate easy drug administration and enhanced acceptance by the patients. Considering daily DOTS as recommended by $\mathrm{WHO}^{28}$ might further optimize dosage and might give much higher expected outcomes.

Second, considering the high relapse and MDR rates, Government of India should think of having long term follow up of the patients treated under the program. Current treatment guidelines allow the patient to be followed up till the end of the treatment. ${ }^{17}$ Many patients will not have even the end treatment sputum follow up done, but labeled as treatment completed. This is confirmed in many of our field observations and during Central Internal Evaluations. This indicator adds up to "Successful treatment outcome" to have much higher chunk, which in fact may not be true. Long term follow up, at least for two years after the completion of the treatment gives scope to identify any adverse outcomes at an early stage to take action.

Third, Government of India should think on supplementing nutrition to TB patients with low body weight along with the treatment. Currently there is no such policy to supplement nutrition to these patients. Many studies note the role of nutrition and BMI in TB treatment outcome. ${ }^{29,30,31}$ Our study also showed indirectly that the patient with low body weight have much higher adverse outcomes indicating nutritional intervention among them may lead to a better situation.

\section{Conclusion}

India has much higher relapse rates among TB patients treated under standardized DOTS regimen. MDR rate among re-treatment TB cases is also very high. While overall reported treatment success rates are stagnant since last few years under standardized treatment regimen, body weight wise desegregated analysis showed high adverse outcomes among those with initial low body weight. Our study showed that one shoe doesn't fit all. Government of India should think to redesign partially individualized treatment regimens 
with weight-band wise daily FDCs and should have a policy to supplement nutrition to those with low body weight. A strategy for long-term follow up would facilitate early identification of adverse outcomes and guide to take remedial action.

\section{Acknowledgement}

This study is conducted and written as a part of theses work for the Masters of Public Health program at Texila American University. The opinion and the statements made are authors direct opinions and in no way concerned with the affiliated institution. The Author acknowledges the help of District TB Officers, Field TB staff of the study districts and State TB Officer, Karnataka in collection and digitalization of data.

\section{Reference}

[1].Agarwal S S, Sehgal S, Lal S S. Public-private mix in the Revised National TB Control Programme. In: Agrawal S P, Chauhan L S, eds. Tuberculosis control in India. New Delhi, India: Directorate General of Health Services, Ministry of Health and Family Wel- fare, 2005.

[2]. Arinaminpathy, N., Batra, D., Khaparde, S., Vualnam, T., Maheshwari, N., Sharma, L. . . Dewan, P. (2016). The number of privately treated tuberculosis cases in India: an estimation from drug sales data. The Lancet Infectious Diseases, 16(11), 1255-1260. doi: https://doi.org/10.1016/S14733099(16)30259-6.

[3].Blomberg, Bjørn, Spinaci, Sergio, Fourie, Bernard, \& Laing, Richard. (2001). The rationale for recommending fixed-dose combination tablets for treatment of tuberculosis. Bulletin of the World Health Organization, 79(1), 61-68. https://dx.doi.org/10.1590/S0042-96862001000100012

[4].Bhargava A, Jain Y. The Revised National Tuberculosis Control Programme in India: Time for Revision of Treatment regimens and rapid up-scaling of DOTS-Plus initiative. National Medical Journal of India 2008;21(4):187-91

[5].Bhargava A, Pai M, et al. - Mismanagement of tuberculosis in India: Causes, consequences, and the way forward - Hypothesis 2011, 9(1): e7.

[6].Bioavailability and Bioequivalence Studies Submitted in NDAs or INDs - General Considerations, available

https://www.fda.gov/downloads/drugs/guidancecomplianceregulatoryinformation/guidances/ucm38937 0.pdf [accessed 25/05/2017]

[7].Drug Resistance in Tuberculosis in India, available at http://icmr.nic.in/ijmr/2004/1010.pdf [accessed 25/05/2017]

[8].David L. Cohn, Flavia Bustreo, Mario C. Raviglione; Drug-Resistant Tuberculosis: Review of the Worldwide Situation and the WHO/IUATLD Global Surveillance Project. Clin Infect Dis 1997; 24 (Supplement_1): S121-S130. doi: 10.1093/clinids/24.Supplement_1.S121

[9].Edginton M, Enarson D, Zachariah R, et al. Why ethics is indispensable for good quality operational research. Public Health Action 2012; 2: 21-22

[10]. Fact sheet for End TB Strategy available at http://who.int/tb/post2015_TBstrategy.pdf?ua=1 [accessed 25/05/2017] Nayak, D. S. S., \& Sahu, D. A. K. (2016). POPULATION GROWTH INDIA'S CURRENT PROBLEMS: AN OVERVIEW. International Educational Scientific Research Journal; Vol 2, No 10 (2016): (OCTOBER), INTERNATIONAL EDUCATIONAL SCIENTIFIC RESEARCH JOURNAL.

[11]. Global TB $\quad$ Report 2016 available at http://apps.who.int/iris/bitstream/10665/250441/1/9789241565394-eng.pdf [accessed 25/05/2017]

[12]. Gupta, D. (2005). Covering a billion with DOTS: My experiences with India s Revised TB Control Programme (1998 2004). New Delhi, 44-77.

[13]. Hanrahan CF et al. Body mass index and risk of tuberculosis and death. AIDS, 2010; 24(10):1501-8. doi: 10.1097/QAD.0b013e32833a2a4a.

[14]. Jinadani A, Borgulya G, de Patino I, Westermann, et, al., (2016). A randomised Phase II trial to evaluate the toxicity of high-dose rifampicin to treat pulmonary tuberculosis. Int J Tuberc Lung Dis 20(6):832-838 
DOI: $10.21522 / \mathrm{TIJPH} .2013 .05 .04 . A r t 047$

ISSN: $2520-3134$

[15]. J. Venom. Anim. Impact of malnutrition on immunity and infection. Toxins incl. Trop. Dis [online]. 2009, vol.15, n.3, pp.374-390. ISSN 1678-9199. http://dx.doi.org/10.1590/S167891992009000300003.

[16]. John, T. J., Dandona, L., Sharma, V. P., \& Kakkar, M. Continuing challenge of infectious diseases in India. The Lancet, 377(9761), 252-269. doi:10.1016/S0140-6736(10)61265-2

[17]. Kumar, A., Gupta, D., Nagaraja, S.B. et al. Indian Pediatr (2013) 50: 301. doi:10.1007/s13312013-0085-1

[18]. Kumar A M V, Naik B, Guddemane D K et. al. (2013) Efficient, quality-assured data capture in operational research through innovative use of open-access technology [Short communication]. PHA 2013; 3(1): 60-62

[19]. Lönnroth K, Williams BG, Cegielski P, Dye C. A consistent log-linear relationship between tuberculosis incidence and body mass index. Int. J. Epidemiol. 2010; 39:149-55. doi: 10.1093/ije/dyp308.

[20]. Martinez, M. N., \& Amidon, G. L. (2002). A Mechanistic Approach to Understanding the Factors Affecting Drug Absorption: A Review of Fundamentals. The Journal of Clinical Pharmacology, 42(6), 620-643. doi:10.1177/00970002042006005

[21]. National Strategic Plan for Tuberculosis elimination, 2017-2025, available at http://tbcindia.nic.in/WriteReadData/NSP\%20Draft\%2020.02.2017\%201.pdf [accessed 25/05/2015]

[22]. Pai, M., \& Temesgen, Z. (2017). Mind the gap: Time to address implementation gaps in tuberculosis diagnosis and treatment. Journal of Clinical Tuberculosis and Other Mycobacterial Diseases, 6, 14-15. doi: https://doi.org/10.1016/j.jctube.2016.02.001

[23]. Pai, M., \& Dewan, P. (2015). Testing and Treating the Missing Millions with Tuberculosis. PLOS Medicine, 12(3), e1001805. doi:10.1371/journal.pmed.1001805

[24]. RNTCP Annual performance report "TB India 2017" available at http://tbcindia.nic.in/WriteReadData/TB\%20India\%202017.pdf [accessed 25/05/2017]

[25]. Raizada, N., Sachdeva, K. S., Sreenivas, A., Kulsange, S., Gupta, R. S., Thakur, R.... Paramsivan, C. N. (2015). Catching the Missing Million: Experiences in Enhancing TB \& DR-TB Detection by Providing Upfront Xpert MTB/RIF Testing for People Living with HIV in India. PLOS ONE, 10(2), e0116721. doi:10.1371/journal.pone.0116721

[26]. Uplekar, M. W., \& Shepard, D. S. (1991). Treatment of tuberculosis by private general practitioners in India. Tubercle, 72(4), 284-290. doi: http://dx.doi.org/10.1016/0041-3879(91)90055-W [27]. Udwadia, Z. F., Pinto, L. M., \& Uplekar, M. W. (2010). Tuberculosis Management by Private Practitioners in Mumbai, India: Has Anything Changed in Two Decades? PLOS ONE, 5(8), e12023. doi:10.1371/journal.pone.0012023

[28]. Von Elm E, Altman DG, Egger M, et al. The Strengthening the Reporting of Observational Studies in Epidemiology (STROBE) statement: guidelines for reporting observational studies. Lancet 2007; 370: 1453-1457

[29]. Yen, Y.-F., Chuang, P.-H., Yen, M.-Y., Lin, S.-Y., Chuang, P., Yuan, M.-J., Deng, C.-Y. (2016). Association of Body Mass Index with Tuberculosis Mortality: A Population-Based Follow-Up Study. Medicine, 95(1), e2300. http://doi.org/10.1097/MD.0000000000002300

[30]. Zachariah R, Spielmann MP, Harries AD, Salanipont FM. Moderate to severe malnutrition in patients with tuberculosis is a risk factor associated with early death. Trans. R. Soc. Trop. Med. Hyg. 2002; 96: 291-4. 


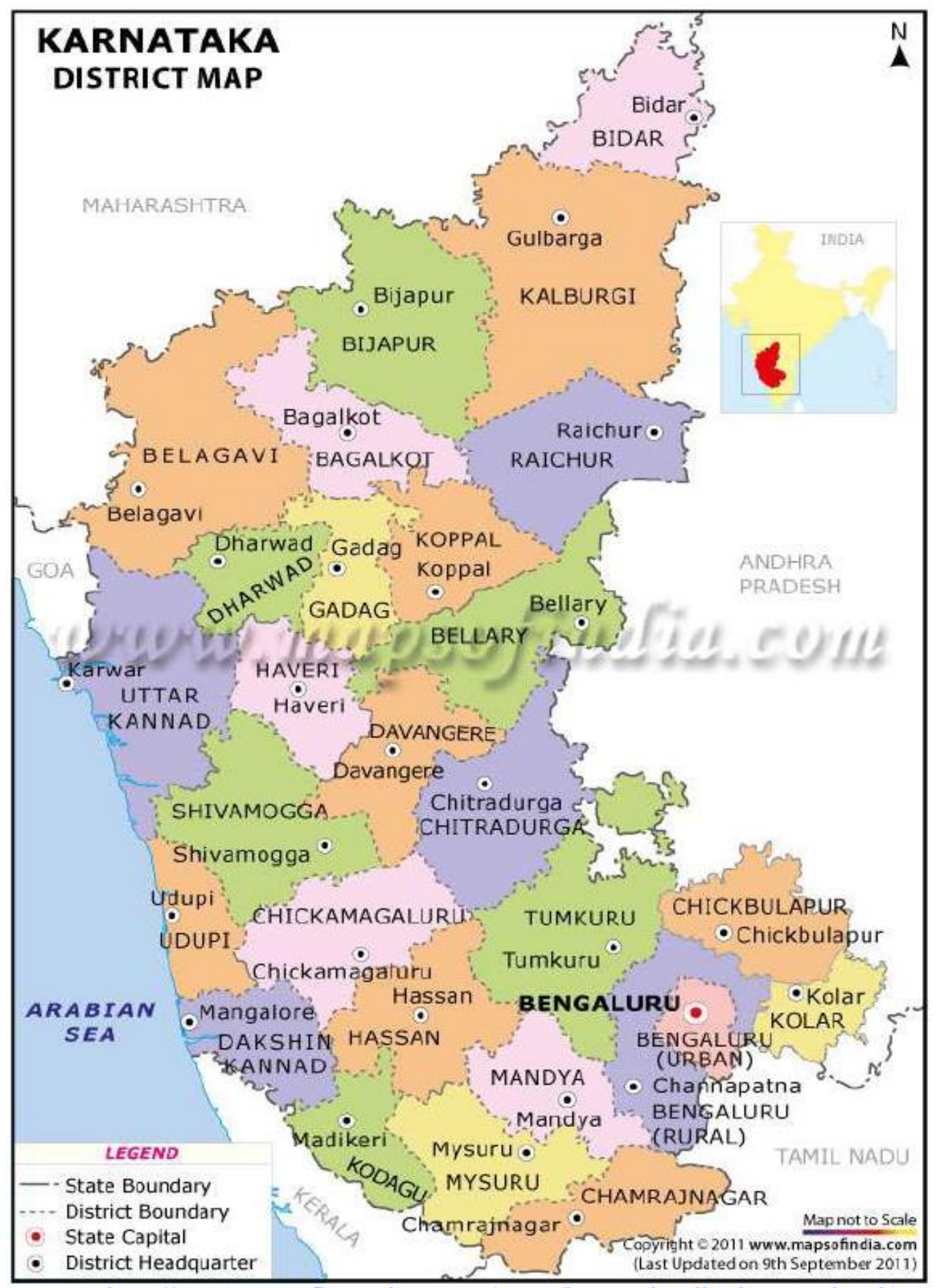

Figure 1. District wise map of karnataka, india

Source: http://www.mapofbangalore.com/maps/karnataka-district-map.html 
DOI: $10.21522 /$ TIJPH.2013.05.04.Art047

ISSN: $2520-3134$

Table 1. Comparison of TB Relapse rates between high TB burden countries, 2011.

\begin{tabular}{|c|c|c|c|c|c|}
\hline Country & $\begin{array}{c}\text { New } \\
\text { Smear } \\
\text { Positive }\end{array}$ & Relapse & Total & $\begin{array}{l}\text { Proportion } \\
\text { of relapse } \\
\text { in } \%\end{array}$ & $\begin{array}{l}\text { 0dds of } \\
\text { relapse in } \\
\text { India as } \\
\text { compared to } \\
(95 \% \mathrm{CI})^{\mathrm{t}}\end{array}$ \\
\hline India & 642321 & 112508 & 754829 & 15 & Reference \\
\hline Afghanistan & 13789 & 1130 & 14919 & 8 & $2.14(2.01-2.27)$ \\
\hline Bangladesh & 98948 & 2701 & 101649 & 3 & $5.6(5.40-5.82)$ \\
\hline Brazil & 40294 & 3555 & 43849 & 8 & $1.99(1.93-2.04)$ \\
\hline Cambodia & 15812 & 367 & 16179 & 2 & $7.55(6.91-8.24)$ \\
\hline China & 377005 & 34610 & 411615 & 8 & $1.91(1.89-1.93)$ \\
\hline DR Congo & 71321 & 3761 & 75082 & 5 & $3.32(3.21-3.43)$ \\
\hline Ethiopia & 49594 & 2143 & 51737 & 4 & $4.05(3.88-4.24)$ \\
\hline Indonesia & 197797 & 5348 & 203145 & 3 & $6.48(6.30-6.66)$ \\
\hline Kenya & 37085 & 3356 & 40441 & 8 & $1.94(1.87-2.01)$ \\
\hline Mozambique & 19537 & 1427 & 20964 & 7 & $2.4(2.27-2.53)$ \\
\hline Myanmar & 42324 & 4606 & 46930 & 10 & $1.61(1.56-1.66)$ \\
\hline Nigeria & 47436 & 2515 & 49951 & 5 & $3.3(3.17-3.44)$ \\
\hline Pakistan & 105733 & 5947 & 111680 & 5 & $3.11(3.03-3.20)$ \\
\hline Philippines & 90876 & 3190 & 94066 & 3 & $4.99(4.81-5.17)$ \\
\hline Russian Federation & 29191 & 8590 & 37781 & 23 & $0.6(0.58-0.61)$ \\
\hline South Africa & 129770 & 18394 & 148164 & 12 & $1.24(1.22-1.26)$ \\
\hline Thailand & 33169 & 1915 & 35084 & 5 & $3.03(2.90-3.18)$ \\
\hline Uganda & 25614 & 1302 & 26916 & 5 & $3.45(3.26-3.65)$ \\
\hline UR Tanzania & 24115 & 1079 & 25194 & 4 & $3.91(3.68-4.16)$ \\
\hline Viet Nam & 50719 & 6925 & 57644 & 12 & $1.28(1.25-1.32)$ \\
\hline Zimbabwe & 12596 & 1444 & 14040 & 10 & $1.53(1.45-1.61)$ \\
\hline High-burden countries excluding India & 1512725 & 114305 & 1627030 & 7 & $2.32(2.30-2.34)$ \\
\hline
\end{tabular}

$\varnothing 95 \%$ CI: 95 percent confidence interval; \%: Percentage.

Source of data: Global TB Report 2012 and India TB Report 2012. 
Table 2. Proportion of multi-drug resistant TB among retreatment cases in high Tb burden countries, 2011

\begin{tabular}{lrc}
\hline Country & $\begin{array}{c}\text { Total } \\
\text { TB } \\
\text { Patients }\end{array}$ & $\begin{array}{c}\text { Proportion of MDR } \\
\text { among RT" patients } \\
\text { Median \% (IQR) }\end{array}$ \\
\hline India & 754829 & $15(13-17)$ \\
Afghanistan & 14919 & \\
Bangladesh & 101649 & $29(24-34)$ \\
Brazil & 43849 & \\
Cambodia & 16179 & \\
China & 411615 & $26(22-30)$ \\
DR Congo & 75082 & $10(2.1-18)$ \\
Ethiopia & 51737 & $12(5.6-21)$ \\
Indonesia & 203145 & $12(8.1-17)$ \\
Kenya & 40441 & \\
Mozambique & 20964 & \\
Myanmar & 46930 & $10(6.9-14)$ \\
Nigeria & 49951 & $10(2.1-18)$ \\
Pakistan & 111680 & $29(2.6-56)$ \\
Philippines & 94066 & $21(14-29)$ \\
Russian Federation & 37781 & $46(41-52)$ \\
South Africa & 148164 & $6.7(5.5-8.1)$ \\
Thailand & 35084 & \\
Uganda & 26916 & \\
UR Tanzania & 25194 & \\
Viet Nam & 57644 & $19(14-25)$ \\
Zimbabwe & 14040 & \\
\hline
\end{tabular}

$\emptyset$ MDR: Multi-Drug Resistant TB cases; \# RT: Re-Treatment TB Cases; € IQR: Interquartile Range

Source of data: Global TB Report 2012 and India TB Report 2012 
DOI: $10.21522 /$ TIJPH.2013.05.04.Art047

ISSN: $2520-3134$

Table 3. Demographic profile of TB patients registered for treatment in gadag and uttara kannada, karnataka, india, 2012.

\begin{tabular}{|c|c|c|c|}
\hline Category & Variable & Number & (Percentage) \\
\hline Total & & 2214 & $(100)$ \\
\hline \multicolumn{4}{|c|}{ Age Group } \\
\hline & $15-24$ years & 360 & (16) \\
\hline & $25-34$ years & 449 & (20) \\
\hline & $35-44$ years & 450 & (20) \\
\hline & $45-54$ years & 430 & (19) \\
\hline & $55-64$ years & 306 & (14) \\
\hline & 65 years and above & 219 & (10) \\
\hline \multicolumn{4}{|c|}{ 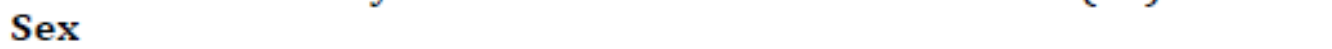 } \\
\hline & Female & 758 & (34) \\
\hline & Male & 1456 & $(66)$ \\
\hline \multicolumn{4}{|c|}{ TU wise patients } \\
\hline & Gadag & 579 & (26) \\
\hline & Honavar & 313 & (14) \\
\hline & Joida & 156 & (7) \\
\hline & Karwar & 242 & (11) \\
\hline & Ron & 559 & (25) \\
\hline & Sirsi & 179 & (8) \\
\hline & Yellapur & 186 & (8) \\
\hline \multicolumn{4}{|c|}{ Type of TB } \\
\hline & New & 1769 & $(80)$ \\
\hline & Relapse & 176 & (8) \\
\hline & Failure & 57 & (3) \\
\hline & Treatment after default & 92 & (4) \\
\hline & Retreatment Others & 120 & (5) \\
\hline \multicolumn{4}{|c|}{ HIV Status } \\
\hline & Negative & 1937 & (88) \\
\hline & Positive & 274 & (12) \\
\hline & Unknown & 3 & (0) \\
\hline
\end{tabular}


Table 4. Overall TB Treatment outcome in Gadag and Uttara Kannada disricts, Karnataka, India, 2012.

\begin{tabular}{|c|c|c|}
\hline & $\begin{array}{c}\text { Gadag } \\
\text { Number (\%) }\end{array}$ & $\begin{array}{r}\text { Uttara Kannada } \\
\text { Number (\%) }\end{array}$ \\
\hline \multicolumn{3}{|l|}{ Initial Weight } \\
\hline Less than $40 \mathrm{kgs}$ & 448 (39) & 346 (32) \\
\hline $40-49.9 \mathrm{kgs}$ & 501 (44) & 502 (47) \\
\hline $50 \mathrm{kgs}$ and above & 189 (17) & $228(21)$ \\
\hline \multicolumn{3}{|l|}{ Treatment outcome } \\
\hline Cured & $604 \quad(53)$ & 465 (43) \\
\hline Treatment completed & $294 \quad(26)$ & $430 \quad(40)$ \\
\hline Defaulted & 106 (9) & $69 \quad(6)$ \\
\hline Died & $108(10)$ & 58 \\
\hline Failure & $26 \quad(2)$ & 46 \\
\hline Transferred out & $\begin{array}{ll}0 & (0)\end{array}$ & (1) \\
\hline Shifted to Cat IV & $\begin{array}{ll}0 & (0)\end{array}$ & $2(0)$ \\
\hline Total & $1138(100)$ & $1076(100)$ \\
\hline
\end{tabular}


DOI: 10.21522/TIJPH.2013.05.04.Art047

ISSN: $2520-3134$

Table 5. Outcomes of TB patients registered for treatment based on their body weight at initiation of treatment in Gadag and Uttara Kannada, Karnataka, India, 2012

\begin{tabular}{|c|c|c|c|c|c|}
\hline $\begin{array}{l}\text { Treatment Outcome } \\
\text { by Type of TB Cases }\end{array}$ & $\begin{array}{c}\text { 30-39.9 kgs } \\
\mathrm{N}(\%)\end{array}$ & $\begin{array}{c}\text { 40-49.9 kgs } \\
\mathrm{N}(\%)\end{array}$ & $\begin{array}{c}50 \text { kgs and above } \\
N(\%)\end{array}$ & $\begin{array}{l}\text { Total } \\
\text { N (\%) }\end{array}$ & \\
\hline \multicolumn{6}{|l|}{ New Cases } \\
\hline Cured & $312(53.8)$ & $417 \quad(52.9)$ & $140(40.2)$ & 869 & $(50.6)$ \\
\hline Treatment Completed & $(29.3)$ & $255(32.4)$ & $168(48.3)$ & 593 & $(34.6)$ \\
\hline Defaulted & (7.1) & $54 \quad(6.9)$ & $19 \quad(5.5)$ & 114 & $(6.6)$ \\
\hline Died & $(8.6)$ & $(5.3)$ & $(5.2)$ & 110 & $(6.4)$ \\
\hline Failed Treatment & $(1.0)$ & $(2.2)$ & $(0.9)$ & 26 & $(1.5)$ \\
\hline Transferred out & $(0.2)$ & $(0.4)$ & $(0.0)$ & 4 & $(0.2)$ \\
\hline Total & $(100)$ & $(100)$ & $(100)$ & 1716 & \\
\hline \multicolumn{6}{|c|}{ Previously Treated Cases } \\
\hline Cured & $(34.5)$ & $96(44.7)$ & $27(39.1)$ & 172 & $(40.4)$ \\
\hline Treatment Completed & $(21.1)$ & $55(25.6)$ & $22(31.9)$ & 107 & $(25.1)$ \\
\hline Defaulted & $(14.1)$ & $30(14.0)$ & $10(14.5)$ & 60 & $(14.1)$ \\
\hline Died & $(14.1)$ & $16 \quad(7.4)$ & $3(4.3)$ & 39 & $(9.2)$ \\
\hline Failed Treatment & ${ }^{\$} 21 \quad(14.8)$ & $(7.9)$ & $(8.7)$ & 44 & $(10.3)$ \\
\hline Transferred out & $1 \quad(0.7)$ & $(0.5)$ & $(0.0)$ & 2 & $(0.5)$ \\
\hline Shifted to Cat IV & $(0.7)$ & $(0.0)$ & $(1.4)$ & 2 & $(0.5)$ \\
\hline Total & $(100)$ & $(100)$ & $(100)$ & 426 & \\
\hline
\end{tabular}

* Chi square $=7.17 \mathrm{df}=2 . \mathrm{P}<0.05$ significant, ${ }^{\wedge}$ Chi square=8.95 df=2. $\mathrm{P}<0.05$ significant, $\$$ Chi square $=6.72 \mathrm{df}=2 . \mathrm{P}<0.05$ significant 